\title{
New Hypotheses and Unanswered Questions in Running Injury Research - comment on Nigg et al.
}

\author{
James Becker ${ }^{1, *}$ \\ 1 Department of Health and Human Development, Montana State University, Bozeman MT US \\ * Corresponding author: Department of Health and Human Development, 121 Hoseaus Fitness Complex, Montana State University, Bozeman, \\ MT 59717, United States, Tel: +1 (406) 994-6854, Fax: +1 (406) 994-6314 \\ Email: james.becker4@montana.edu
}

\section{COMMENTARY}

\section{Article History:}

Submitted $10^{\text {th }}$ February 2018

Accepted $1^{\text {st }}$ March 2018

Published 14 ${ }^{\text {th }}$ May 2018

Handling Editor:

Markus Tilp

Karl-Franzens-University Graz, Austria

Editor-in-Chief:

Martin Kopp

University of Innsbruck, Austria

\begin{abstract}
After critical evaluation of the evidence, Nigg et al.'s target article reject currently discussed hypotheses regarding relationships between impact forces, pronation, and running injuries. In doing so, they highlight methodological questions underlying research in this field. This commentary focuses on three such questions including: how are impact forces and the relationship between impact and injury being quantified, what are the methods currently used to measure foot pronation and what are metrics being extracted, and the importance of focusing on individual response patterns. Each of these areas represents important venues for continued development in the field of running biomechanics and running injuries.
\end{abstract}

Keywords:

Impact forces - frequency analysis - pronation - single subject analysis

Citation:

Becker, J. (2018): New Hypotheses and Unanswered Questions in Running Injury Research - comment on Nigg et al. Current Issues in Sport Science, 3:102. doi: 10.15203/CISS_2018.102

This is a commentary on a CISS report article authored by Nigg, B. M., Mohr, M. \& Nigg, S. R. (2017). Muscle tuning and preferred movement path - a paradigm shift. Current Issues in Sport Science, 2:007. doi: 10.15203/CISS_2017.007

\section{Introduction}

The target article by Nigg et al. (2017) challenges decades of research regarding whether impact forces or excessive pronation are related to running injuries. Instead they propose two new paradigms:muscle tuning and the preferred movement path. In discussing the implications of these concepts, the authors emphasize how individuals can respond differently to a given intervention and thus recommend the need to focus on functional groups who respond similarly. Underlying the development of the paradigms proposed by Nigg et al. (2017) are questions regarding consistency or inconsistencies in the methodologies and approaches currently used in running biomechanics research. This commentary will consider each of these areas while posing questions for the running research community to consider in future research.

\section{Impact Forces}

Nigg et al. (2017) conclude there is little evidence supporting the relationship between impact forces and running injuries and, as an alternative, propose the hypothesis of muscle tuning. There is preliminary evidence suggesting that muscle tuning happens during running (Boyer \& Nigg, 2006, 2004), and this hypothesis should be further investigated, especially in prospective studies related to injury development. However, one could also ask if the reason epidemiologic studies have not shown a clear link between impact forces and running injuries is that the epidemiologic studies have not actually been measuring true impact forces. Spectral analysis of ground reaction forces during running reveals that the classic "impact peak" results from the superposition of high frequency content from the impact between the foot and the ground and low fre- 
quency content representing the movement of the rest of the body mass (Shorten \& Mientjes, 2011). These high frequency impact components are present in the ground reaction force signal even when an "impact peak" may not be discernable in the time domain (Gruber, Davis, \& Hamill, 2011; Gruber, Edwards, Hamill, Derrick, \& Boyer, 2015). Thus, only analyzing the "impact peak" in the time domain can lead to erroneous conclusions. For example, Shorten and Mientjes (2011) showed that when comparing shoes with three different levels of cushioning, a time domain analysis of the "impact peak" suggested the softest shoe had the highest "impact peak". In contrast, the frequency domain analysis revealed the high frequency impact components were attenuated in the softest shoe. However, because they occurred later in stance, they were summed with more low frequency content and thus, the higher "impact peak" in the time domain. Without analyzing the true impact components one might have mistakenly concluded the soft shoe increased impact forces.

While several prospective studies evaluating relationships between impact forces and injury have been conducted (Bredeweg, Buist, \& Kluitenberg, 2013; Davis, Bowser, \& Mullineaux, 2016; Messier et al., 2016) these studies have all examined the "impact peak" or loading rates in the time domain. Considering the discrepancies between analyzing impact forces in the time and frequency domains, one could question whether these studies actually reveal information about the relationship between impacts and running injuries, and by extension, should we reject the association between impacts and running injuries, as advocated in the target article? Or, is it more accurate to say that we really don't know whether there is a relationship as, to date, no prospective studies on running injuries and impact forces have actually quantified impacts and instead focused on the time domain measures of "impact peak" or loading rates?

\section{Pronation}

As with impact forces, Nigg et al. (2017) systematically critique the evidence linking "excessive" pronation with running injuries and conclude there is not enough evidence to support the relationship. However, one needs to ask whether this lack of relationship is due to one not existing, or due to the methods currently being used in the literature for measuring this parameter. Pronation is a complex movement involving motion in multiple planes at multiple joints and the movement of the individual joints involved is difficult to measure. Some authors have attempted to account for this complexity by calculating ankle movement about an anatomical subtalar joint axis (O'Connor \& Hamill, 2005) or summing motion about multiple axes to calculate three dimensional pronation (Willems, Witvrouw, De Cock, \& De Clercq, 2007). However, most running studies place three markers on the shoe heel counter and calculate rearfoot eversion about the long axis of the foot as a surrogate measure of pronation. Should this continue to be acceptable or should more anatomically relevant measures of joint motion be encouraged?

Additionally, there are several other questions which should be addressed before rejecting the hypothesis that abnormal pronation may be related to running injuries. For example, what constitutes "excessive" pronation? There is no consensus definition. Is there a relationship between amounts of pronation and tissue loading? Musculoskeletal modeling has provided insights into numerous running injuries including iliotibial band syndrome (Hamill, Miller, Noehren, \& Davis, 2008), patellofemoral pain syndrome (Besier, Fredericson, Gold, Beaupre, \& Delp, 2009), and tibial, femoral, and metatarsal stress fractures (Edwards, Gillette, Thomas, \& Derrick, 2008; Edwards, Taylor, Rudolphi, Gillette, \& Derrick, 2009; Firminger, Fung, Loundagin, \& Edwards, 2017). These same strategies could be brought to bear on the question of whether the amount of pronation is related to tissue loading. What about alternative hypotheses such as the amount of pronation used as a function of total joint range of motion available (Rodrigues, TenBroek, \& Hamill, 2013) or the duration of pronation instead of the amount (Becker, James, Wayner, Osternig, \& Chou, 2017). While the preferred movement path concept should continue to be developed, these other question are examples of areas which should be examined in greater depth before rejecting the hypothesis that abnormal pronation may be related to muscle injury.

\section{Functional Groups}

Nigg et al. (2017) conclude the target article by presenting the concept of functional groups, which they define as a group of subjects that reacts the same way to some type of intervention. The concept of studying each individual and how they respond to a given intervention is not new in biomechanics literature. In a series of studies from the 1990s Bates and colleagues demonstrated how individualized, subject specific responses could be observed when evaluating impact forces while running with different shoes (Bates, Osternig, \& Sawhill, 1983; Dufek \& Bates, 1991; Dufek, Bates, Stergiou, \& James, 1995) or when landing from drop jumps (Caster \& Bates, 1995; Dufek et al., 1995; Schot, Bates, \& Dufek, 1994). As such, Bates advocated for using single subject analyses, saying that no two individuals are identical and, when one considers the plasticity of the neuromuscular system, we have an almost infinite number of degrees of freedom which can be used to control any given action (Bates, 1996). Such individualized responses are highlighted by Nigg et al. (2017) with the example of how the same heel wedges can results in different changes in the center of pressure trajectories and corresponding knee abduction moments across subjects.

While Bates and colleagues have presented several innovative methods for single subject data analysis (Bates, 1996; Bates, Dufek, \& Davis, 1992) these approaches still present challenges, especially when it comes to generalizing results to larger populations (Reboussin \& Moran, 1996). In this regard, the approach 
suggested in the target article by Nigg et al. (2017) represents a potentially powerful shift in research design in biomechanics studies. Their recommendation to vectorize the data and use analysis techniques such as principal component analysis or classification algorithms such as support vector machines for detecting group differences provides a powerful tool for identifying functional groups while conceptually recognizing that individualized response patterns likely exist. To date, while such approaches have not been used with high frequency, they have demonstrated the ability to distinguish specific kinematics between groups of runners (Foch \& Milner, 2014; Phinyomark, Hettinga, Osis, \& Ferber, 2015). It seems logical that such approaches will only grow in popularity in the coming years and provide new insights into relationships between running mechanics and injury.

\section{Conclusion}

The hypotheses presented by Nigg et al. (2017) in their target paper are valuable additions to the running biomechanics field. While they require further study and validation the process of doing so will force the field to also reconsider long held beliefs and commonly used methodologies. Perhaps the combination of these efforts might start finally making a positive dent in the incidence and nature of running injuries.

\section{Funding}

The author has no funding or support to report.

\section{Competing Interests}

The author has declared that no competing interests exist.

\section{Data Availability Statement}

All relevant data are within the paper.

\section{References}

Bates, B. (1996). Single-subject methodology: An alternative approach. Medicine \& Science in Sports \& Exercise, 28(5), 631-638.

Bates, B., Dufek, J., \& Davis, H. (1992). The effect of trial size on statistical power. Medicine \& Science in Sports \& Exercise1, 24(9), 1059-1068.

Bates, B., Osternig, L., \& Sawhill, J. (1983). An assessment of subject variability, subject-shoe ineraction, and the evaluation of running shoes using ground reaction force data. Journal of Biomechanics, 16(3), 181-191.
Becker, J., James, S., Wayner, R., Osternig, L., \& Chou, L.-S. (2017). Biomechanical Factors Associated With Achilles Tendinopathy and Medial Tibial Stress Syndrome in Runners. The American Journal of Sports Medicine, 45(11), 2614-2621.

Besier, T., Fredericson, M., Gold, G., Beaupre, G., \& Delp, S. L. (2009). Knee muscle forces during walking and running in patellofemoral pain patients and pain free controls. Journal of Biomechanics, 42(7), 898-905.

Boyer, K. A., \& Nigg, B. (2006). MuscleTuning During Running:Implications of an Un-tuned Landing. Journal of Biomechanical Engineering, 128(6), 815. http://doi.org/10.1115/1.2354202

Boyer, K. A., \& Nigg, B. M. (2004). Muscle activity in the leg is tuned in response to impact force characteristics. Journal of Biomechanics, 37(10), 1583-1588. http://doi.org/10.1016/ j.jbiomech.2004.01.002

Bredeweg, S. W., Buist, I., \& Kluitenberg, B. (2013). Differences in kinetic variables between injured and noninjured novice runners: a prospective cohort stud. Journal of Science and Medicine in Sport, 16, 205-210.

Caster, B., \& Bates, B. (1995). The assessment of mechanical and neuromuscular response strategies during landing. Medicine \& Science in Sports \& Exercise, 27(5), 736-744.

Davis, I. S., Bowser, B. J., \& Mullineaux, D. R. (2016). Greater vertical impact loading in female runners with medically diagnosed injuries: A prospective investigation. British Journal of Sports Medicine, 50(14), 887-892.

Dufek, J., \& Bates, B. (1991). Dynamic performance assessment of selected sport shoes on impact forces. Medicine \& Science in Sports \& Exercise, 23(9), 1062-1067.

Dufek, J., Bates, B., Stergiou, N., \& James, C. R. (1995). Interactive effects between group and single subject response patterns. Human Movement Science, 14, 301-323.

Edwards, W. B., Gillette, J. C., Thomas, J. M., \& Derrick, T. R. (2008). Internal femoral forces and moments during running: Implications for stress fracture development. Clinical Biomechanics, 23(10), 1269-1278.

Edwards, W. B., Taylor, D., Rudolphi, T. J., Gillette, J. C., \& Derrick, T. R. (2009). Effects of stride length and running mileage on a probabilistic stress fracture model. Medicine and Science in Sports and Exercise, 41(12), 2177-2184. http://doi. org/10.1249/MSS.0b013e3181a984c4

Firminger, C., Fung, A., Loundagin, L., \& Edwards, W. B. (2017). Effects of footwear and stride length on metatarsal strains and failure in running. Clinical Biomechanics, 49, 8-15.

Foch, E., \& Milner, C. E. (2014). The influence of iliotibial band syndrome history on running biomechanics examined via principal components analysis. Journal of Biomechanics, 47(1), 81-86. http://doi.org/10.1016/j.jbiomech.2013.10.008

Gruber, A., Davis, I., \& Hamill, J. (2011). Frequency Content of the Vertical Ground Reaction Force Component During Rearfoot and Forefoot Running Patterns. Medicine \& Science in Sports \& Exercise, 43(5), 60. http://doi.org/10.1249/01. MSS.0000402852.25234.f0

Gruber, A., Edwards, W., Hamill, J., Derrick, T., \& Boyer, K. (2015). Ground Reaction Forces in Rearfoot and Forefoot Run- 
ning Assessed By a Continuous Wavelet Transform. Medicine \& Science in Sports \& Exercise, 47(5S), 710. http://doi. org/10.1249/01.MSS.0000478661.95317.63

Hamill, J., Miller, R., Noehren, B., \& Davis, I. (2008). A prospective study of iliotibial band strain in runners. Clinical Biomechanics, 23(8), 1018-1025. http://doi.org/10.1016/j.clinbiomech.2008.04.017

Messier, S., Martin, D., Mihalko, S., Ip, E., DeVita, P., Cannon, W., ... Seay, J. (2016). A 2-Year Prospective Observational Study to Determine The Etiologic Factors Associated with Overuse Running Injuries. Medicine \& Science in Sports \& Exercise, 48(5S), 170-171.

Nigg, B., Mohr, M., \& Nigg, S. (2017). Muscle tuning and preferred movement path - a paradigm shift. Current Issues in Sport Science, 2. http://doi.org/10.15203/CISS_2017.007

O'Connor, K. M. O., \& Hamill, J. (2005). Frontal Plan Moments Do Not Accurately Reflect Ankle Dynamics During Running. Journal of Applied Biomechanics, 21, 85-95.

Phinyomark, A., Hettinga, B. A., Osis, S., \& Ferber, R. (2015). Do intermediate- and higher-order principal components contain useful information to detect subtle changes in lower extremity biomechanics during running? Human Movement Science, 44, 91-101. http://doi.org/10.1016/j. humov.2015.08.018

Reboussin, D., \& Moran, T. (1996). Statistical consideration in the use and analysis of single-subject designs. Medicine \& Science in Sports \& Exercise, 28(5), 639-644.

Rodrigues, P., TenBroek, T., \& Hamill, J. (2013). Runners with anterior knee pain use a greater percentage of their available pronation range of motion. Journal of Applied Biomechanics, 29(2), 141-146.

Schot, P. K., Bates, B. T., \& Dufek, J. S. (1994). Bilateral performance symmetry during drop landing: a kinetic analysis. Medicine and Science in Sports and Exercise, 26(9), 1153-9. http://doi.org/10.1249/00005768-199409000-00013

Shorten, M., \& Mientjes, M. I. V. (2011). The "heel impact" force peak during running is neither "heel" nor "impact" and does not quantify shoe cushioning effects. Footwear Science, 3(1), 41-58. http://doi.org/10.1080/19424280.2010.542186

Willems, T. M., Witvrouw, E., De Cock, A., \& De Clercq, D. (2007). Gait-related risk factors for exercise-related lower-leg pain during shod running. Medicine and Science in Sports and Exercise, 39(2), 330-339. 